\title{
ẢNH HƯởNG CỦA ĐIỀU KIỆN TỬ NHIÊN ĐẾN SỰ HÌNH THÀNH PHONG CÁCH NGƯỜI ĐÀ LẠT
}

\author{
Trần Thị Hiền ${ }^{\mathrm{a}^{*}}$
}

${ }^{a}$ Khoa Ngũ văn và Lịch sủ, Truò̀ng Đại học Đà Lạt, Lâm Đồng, Việt Nam

"Tác giả liên hệ: Email: hientt@dlu.edu.vn

Lịch sử bài báo

Nhận ngày 22 tháng 01 năm 2020

Chỉnh sửa ngày 20 tháng 02 năm 2020 | Chấp nhận đăng ngày 25 tháng 02 năm 2020

\section{Tóm tắt}

Dựa trên nguồn tu liệu điền dã kết hơp với nhũng nghiên cứu liên quan, bài viết phân tích nhũng ảnh hưởng của điều kiện tự nhiên đến sư hình thành phong cách của người Đà Lạt. Kết quả cho thấy, nhũ̃ng yếu tố môi truờng sinh thái tự nhiên đặc thù của vùng cao nguyên Lang Biang nhu khi hậu, địa hình, và cảnh quan đã góp phần hình thành đặc điểm "hiền hòa, thanh lịch, mến khách" trong khuôn mẫu văn hóa, hành vi, và ưng xủ của nguời Đà Lạt. Vì vậ, khi bàn đến nhũng giải pháp để giũ gìn và phát huy phong cách nguời Đà Lạt, cần thiết quan tâm đến việc bảo tồn và tôn tạo cảnh quan, môi truờng sinh thái của đô thị cao nguyên này.

Từ khóa: Đà Lạt; Hiền hòa; Mến khách; Phong cách người Đà Lạt; Thanh lịch.

DOI: http://dx.doi.org/10.37569/DalatUniversity.10.1.713(2020)

Loại bài báo: Bài báo nghiên cứu gốc có bình duyệt

Bản quyền @ 2020 (Các) Tác giả.

Cấp phép: Bài báo này được cấp phép theo CC BY-NC 4.0 


\title{
THE IMPACT OF NATURE ON THE LIFESTYLE OF DALAT PEOPLE
}

\author{
Tran Thi Hien ${ }^{\mathrm{a}^{*}}$
}

${ }^{a}$ The Faculty of Literature and History, Dalat University, Lamdong, Vietnam

*Corresponding author: Email: hientt@dlu.edu.vn

\section{Article history}

Received: January $22^{\text {nd }}, 2020$

Received in revised form: February $20^{\text {th }}, 2020 \mid$ Accepted: February $25^{\text {th }}, 2020$

\begin{abstract}
Based on the fieldwork data and some relevant studies, the article analyzes the impact of nature on forming the lifestyle of Dalat people. The study shows that some specific natural ecological environment factors of Lang Biang Highland including the climate, terrain, and landscape have played a role in shaping the "gentle, elegant, and hospitable" feature in cultural patterns, conducts, and behaviors of Dalat people. Therefore, in discussions on how to preserve and promote the lifestyle of Dalat people, it should be brought into consideration the conservation and restoration of the landscapes and the ecological environment of this plateau town.
\end{abstract}

Keywords: Dalat; Dalat People's lifestyle; Elegance; Gentleness; Hospitality.

DOI: http://dx.doi.org/10.37569/DalatUniversity.10.1.713(2020)

Article type: (peer-reviewed) Full-length research article

Copyright $(92020$ The author(s).

Licensing: This article is licensed under a CC BY-NC 4.0 


\section{1. ĐặT VẤN ĐỀ}

Trong hệ thống đô thị Việt Nam, Đà Lạt là một thành phố khá trẻ, với gần 130 năm hình thành và phát triển. Tuy nhiên, với những đặc điểm rất riêng về điều kiện tự nhiên, cảnh quan, kiến trúc, văn hóa... đã tạo nên cho đô thị này một diện mạo độc đáo và đầy hấp dẫn. Chính vì vậy, từ lâu, Đà Lạt đã trở thành một địa danh du lịch nổi tiếng không chỉ ở Việt Nam, mà đã vươn ra tầm khu vực và thế giới. Đà Lạt được du khách thập phương yêu mến, dành cho nhiều mỹ từ như "thành phố ngàn hoa", "thành phố của tình yêu", "thiên đường du lịch", "tiểu Paris ở Đông Dương”... Bên cạnh sự hấp dẫn của cảnh sắc thiên nhiên, Đà Lạt còn được yêu quý và trân trọng vì cộng đồng cư dân nơi đây đã định hình một phong cách sống riêng-phong cách "hiền hòa, thanh lịch, và mến khách". Phong cách đó được biểu hiện đa dạng trên nhiều phương diện hành vi và văn hóa ứng xử, trở thành hệ thống giá trị chung, được các thế hệ người Đà Lạt tự hào, và có ý thức nâng niu và gìn giữ. Theo các nhà nghiên cứu, phong cách sống của người Đà Lạt có nguồn gốc từ tổng hòa nhiều nhân tố khác nhau: Điều kiện tự nhiên; Ảnh hưởng của lối sống và văn hóa Pháp; Sự đa dạng của nguồn gốc dân cư; Đặc thù nghề nghiệp việc làm của cư dân Đà Lạt... Dựa trên nguồn tư liệu điền dã kết hợp với những nghiên cứu liên quan, bài viết này phân tích những ảnh hưởng của điều kiện tự nhiên đến sự hình thành phong cách của người Đà Lạt và đóng góp thêm nguồn tư liệu về thành phố trên cao nguyên Lang Biang.

\section{MộT SỔ QUAN ĐIỂM VỂ MỐI QUAN HỆ GIỬA ĐIỀU KIỆN TỬ NHIÊN, VĂN HÓA, VÀ PHONG CÁCH SỐNG}

Điều kiện tự nhiên hay môi trường tự nhiên là một thực thể được hình thành bên ngoài con người. Trong đó, con người được xem là nhân tố "sinh sau đẻ muộn", nằm trong tổng hòa các mối quan hệ của tự nhiên và bị chi phối bởi tự nhiên. Do đó, trước khi nói đến các điều kiện về môi trường xã hội thì con người phải luôn chịu sự tác động và chi phối bởi những điều kiện của môi trường tự nhiên nơi mình sinh sống. Tuy nhiên, là một thực thể sống động và có tư duy phát triển, con người đã dần có được khả năng tự điều chỉnh mình để thích nghi với môi trường tự nhiên. Đồng thời, con người cũng có sự can thiệp, cải tạo môi trường tự nhiên để nó có thể phát huy hơn những lợi thế của mình để phục vụ cho chính họ. Giữa con người và môi trường tự nhiên luôn có mối quan hệ khăng khít và tác động qua lại lẫn nhau. Trong đó, môi trường tự nhiên là tác nhân, là điều kiện để con người sáng tạo ra các giá trị văn hóa; Ngược lại, chính những giá trị văn hóa do con người sáng tạo dựa trên nền tảng của môi trường tự nhiên đó lại là nhân tố tạo đà cho các điều kiện tự nhiên ngày càng bộc lộ được vai trò của mình nhiều hơn. Ngoài ra, trong một mức độ nào đó, môi trường đã đặt ra những thách đố và con người bắt buộc phải giải quyết chúng. Môi trường khác nhau thì thách đố sẽ khác nhau và lúc đó con người sẽ có những ứng xử cũng khác nhau (Phạm, 2002, tr.62).

Julian Haynes Steward-người đề xướng ra trường phái sinh thái học văn hóa (cultural ecology) vào những năm 1950 đã nhấn mạnh tầm quan trọng của môi trường sinh thái tự nhiên trong sự biến đổi mang tính tiến hóa của văn hóa. Trong đó, ông đã đề cập đến mối quan hệ giữa văn hóa và môi trường từ quan điểm con người, là thực thể tồn tại thích ứng với môi trường thông qua văn hóa, còn văn hóa thì chịu ảnh hưởng lớn của 
các loại tài nguyên môi trường mà con người sử dụng (trích trong Vũ, 2004, tr. 172). Con người và môi trường là hai yếu tố có sự gắn bó mật thiết với nhau. Cùng với các nhân tố từ môi trường xã hội, môi trường tự nhiên đã góp phần tạo nên những đặc trưng về văn hóa từng nhóm cộng đồng cư dân hay từng vùng, miền. Là một thành tố của đời sống văn hóa và góp phần hình thành nên bản sắc địa phương của một cộng đồng, phong cách sống (lifestyle) cũng chịu sự ảnh hưởng và chi phối mạnh mẽ của môi trường sinh thái tự nhiên. Có nhiều khái niệm khác nhau về phong cách sống. Nguyễn $(2019$, tr. 45$)$ cho rằng “phong cách là những đặc tính tâm lý văn hóa mang tính trội (tiêu biểu và điển hình) thể hiện qua hành vi và cách ứng xử trong giao tiếp (dáng vẻ, sắc thái bề ngoài, và ngôn từ), phản ánh nhân cách và phẩm giá của cá nhân và của cộng đồng. Phong cách phản ánh tâm tính có tính chắt lọc, tinh hoa của một cộng đồng”. Theo Trương $(2018, \operatorname{tr} 10)$, phong cách sống là những nét điển hình, được lặp đi lặp lại và định hình thành phong cách riêng và thói quen trong đời sống cá nhân, nhóm xã hội, dân tộc, hay là cả một nền văn hóa. Phong cách sống được hình thành dựa trên các yếu tố tự nhiên, kinh tế, xã hội, và văn hóa của môi trường sống, được thể hiện trong đời sống hàng ngày như thông qua các biểu hiện cụ thể về hành vi thực tiễn trong trang trí nhà ở, phong cách ăn mặc, và văn hóa ứng xử.Như vậy, cùng với môi trường nhân văn thì điều kiện sinh thái tự nhiên có ảnh hưởng nhất định đến sự hình thành những đặc trưng trong đời sống văn hóa nói chung, những khuôn mẫu ứng xử văn hóa nói riêng của một cộng đồng cư dân trong những giai đoạn lịch sử nhất định. Chính vì vậy, khi nghiên cứu và phân tích những yếu tố góp phần hình thành nên phong cách sống của người Đà Lạt, không thể bỏ qua tác động của các điều kiện khí hậu, địa hình, cảnh quan... đặc trưng của vùng cao nguyên Lang Biang.

\section{3. ĐIỀU KIỆn TỰ NHIÊN VÀ SỰ HİNH THÀNH PHONG CÁCH SỐNG CỦA NGƯỜI ĐÄ LẠT}

Trước khi được bác sĩ A. Yersin phát hiện vào năm 1893, Đà Lạt là vùng đất sinh sống của người Lạch (Lat) ${ }^{1}$. Địa danh Đà Lạt có nguồn gốc từ ngôn ngữ của cư dân này: Đạ nghĩa là nước/sông/suối và Lạt là tên gọi của nhóm cư dân sống lâu đời ở vùng cao nguyên Lang Biang. Người Lạch có đời sống giản dị, gần gũi, thân thiện với môi trường tự nhiên, và sùng bái nhiều thế lực siêu nhiên. Họ có tính cách ôn hòa, hiền lành, chất phác, và đề cao tính cộng đồng. Về sau, do nhu cầu tìm kiếm một "viện nghỉ dưỡng" dành cho các sĩ quan và binh lính Pháp, Đà Lạt đã được lựa chọn, khởi đầu cho lịch sử hình thành và phát triển của đô thị này ${ }^{2}$. Theo như yêu cầu được đưa ra của toàn quyền Paul Doumer, việc chọn một nơi nghỉ dưỡng phải đủ bốn điều kiện cần thiết: Độ cao tối thiểu

\footnotetext{
${ }^{1}$ Theo Danh muc các thành phần dân tộc Việt Nam do Tổng cục Thống kê Nhà nước công bố 02/3/1979, người Cơ ho Lạch hay còn gọi là người Lạch là một nhóm địa phương của tộc người Cơ ho (người Cơ ho có sáu nhóm địa phương: Co ho Xrê, Cơ ho Nộp, Cơ ho Cơ dòn, Cơ ho Chil, Cơ ho Lạch, Cơ ho T'rinh).

${ }^{2}$ Điều này đã diễn ra bởi trong công cuộc khai thác thuộc địa của thực dân Pháp tại Đông Dương, họ đã gặp phải một trở ngại lớn về vấn đề thời tiết là gây ra sự chết chóc, bệnh dịch cho lực lượng của họ. Số lượng binh sĩ Pháp đã bị thiệt mạng quá nhiều "nghĩa trang sát quân y viện Sài Gòn còn đông hơn cả một thành phố lớn ở Âu châu"... Tướng Theóphile Pennequin cho rằng "người ta không thể thích nghi với thuộc địa, mỗi ngày trôi qua là một ngày sức lực bị bào mòn. Nam Kỳ là một con quái vật ăn thịt người khủng khiếp" (Eric, 2015, tr.22-79). Các vấn đề về sức khỏe binh lính, sĩ quan, và dân định cư Pháp hơn lúc nào hết là mối quan ngại được đặt lên hàng đầu. Do đó, Toàn quyền Paul Doumer đã chỉ thị cho các thuộc cấp thu thập thông tin khả dĩ cho việc xây dựng một viện nghỉ dưỡng cho người Pháp để họ có thể lấy lại sức lực, tránh được các bệnh dịch vùng nhiệt đới. Và điều này thật may mắn cho Paul Doumer khi bác sĩ Alexandre Yersin đã ghi lại toàn bộ những điều mắt thấy, tai nghe về vùng đất Lang Biang này (tên được $\mathrm{A}$. Yersin gọi cho Đà Lạt trước đó) trong những chuyến thám hiểm của mình từ các năm 1892, 1893, và 1894 (Eric, 2015, tr. 41).
} 
1,200 m, nguồn nước dồi dào, đất đai trồng trọt được và khả năng thiết lập đường giao thông dễ dàng. So với nhiều địa phương khác mà người Pháp từng khảo sát để chọn làm nơi xây dựng viện nghỉ dưỡng như Bà Nà, Vũng Tàu, Ba Vì... thì Đà Lạt có nhiều nét đáng chú ý và nổi trội hơn cả. Ba Vì thì quá chật hẹp, độ ẩm quá cao; Vùng cao nguyên nằm giữa sông Hồng và sông Đà thì đường giao thông không thuận lợi; Vũng Tàu có bãi biển, mát mẻ hơn nhưng không thích hợp cho việc xây dựng khu nghỉ dưỡng vì ở đây có vùng đầm lầy dài hàng chục cây số, là môi trường cho bệnh sốt rét phát triển; Nam Kỳ và Campuchia không có những ngọn núi cao trên 1,000 m (Nguyễn, 2018, tr. 110). Trong khi đó, Đà Lạt có độ cao trung bình $1,500 \mathrm{~m}$ so với mặt nước biển, địa hình nhiều đồi núi quanh co và uốn lượn tạo nên một cảnh sắc lãng mạn và riêng biệt. Mật độ che phủ của cây xanh lớn, xen kẽ giữa các sườn đồi nhấp nhô là cảnh quan thung lũng, hồ nước với rừng cây và trảng cỏ đã tạo nên một bức tranh tuyệt mỹ. Bên cạnh đó, Đà Lạt còn có khí hậu ôn hòa, không khí trong lành và mát mẻ quanh năm. Một năm có hai mùa là mùa mưa và mùa khô. Mùa mưa bắt đầu từ tháng 4 đến cuối tháng 10 và mùa khô bắt đầu từ tháng 11 đến cuối tháng 3 năm sau. Lượng mưa trung bình năm đạt $1,739 \mathrm{~mm}$. Trong đó, lượng mưa chủ yếu tập trung vào ba tháng 7,9 , và 10 . Nhiệt độ trung bình vào mùa này là 20 ${ }^{\circ} \mathrm{C}$. Mùa khô có nhiệt độ trung bình là $18^{\circ} \mathrm{C}$ vào ban ngày vào khoảng $5^{\circ} \mathrm{C}$ vào ban đêm, trời lạnh và khô. Độ ẩm ở đây bao giờ cũng thấp hơn so với đồng bằng (dao động từ $66 \%$ đến $80 \%$ vào mùa mưa và từ $50 \%$ đến $60 \%$ vào mùa khô). Buổi sáng thường khô hơn buổi chiều nhưng trên cao nguyên, thông mọc thưa và gió thổi đều nên hơi nước thoát nhanh (Nguyễn, 2018, tr. 165). Khí hậu ở Đà Lạt tương đối ổn định, hầu như không có các hiện tượng thời tiết cực đoan, không xảy ra các hiện tượng bão lũ, hay khô hạn. Thỉnh thoảng mới xuất hiện các hiện tượng mưa đá và sương muối có tác động đến sản xuất nông nghiệp nhưng nhìn chung không gây thiệt hại đáng kể. Chính lợi thế về khí hậu, địa hình, và cảnh quan là yếu tố hàng đầu để người Pháp quyết định lựa chọn và quy hoạch phát triển đô thị Đà Lạt. Năm 1901, toàn quyền Paul Doumer viết: "Đà Lạt vốn được phú cho khí hậu và sự lành mạnh vô song, đã dứt khoát được chọn làm trạm điều dưỡng tương lai". Kiến trúc sư J. Lagisquet khẳng định: "Không ai có thể phủ nhận Đà Lạt chiếm một vị trí đặc biệt thuận lợi ở Viễn Đông, khí hậu, danh lam thắng cảnh, tiềm năng phát triển làm cho Đà Lạt thành một nơi được ưu đãi, không nơi nào có thể so sánh được. Đà Lạt có thể và phải trở thành một nơi nghỉ mát lớn ở Viễn Đông"; "với núi đồi xanh tươi gợi nhớ những dãy núi Alpes và Vosges ở châu Âu, không khí trong lành, khí hậu mát mẻ, cách bờ biển $80 \mathrm{~km}$ theo đường chim bay, Đà Lạt đã đáp ứng được tất cả những yêu cầu của một nơi nghỉ dưỡng trong vùng nhiệt đới với những ai muốn tắm mình trong sự yên tĩnh và tìm thấy sự cân bằng, niềm vui trong cuộc sống" (trích trong Nguyễn, 2018, tr. 162-200); hay như lời kể của bác sĩ Tardif về những đêm đầu tiên của ông ở Lang Biang năm 1899: "Trời lạnh mới ngủ ngon làm sao! Bốn tháng rồi tôi đã không cảm thấy thỏa mái như vậy. Một làn sương mỏng bao trùm cảnh vật. Thực sự tôi đang ở thuộc địa hay là ở Pháp, giữa màn sương của sông Rhône vây phủ” (Eric, 2015, tr. 151).

Ngay từ đầu, việc xây dựng thành phố Đà Lạt đã được người Pháp đưa vào khuôn mẫu rất rõ ràng theo nguyên tắc tránh tối đa việc phá vỡ cảnh quan thiên nhiên, đảm bảo cho con người có thể hòa mình vào không gian tĩnh lặng của tự nhiên, tận hưởng khí hậu trong lành, mát mẻ, và xứng đáng với danh hiệu "thiên đường dành cho sự nghỉ dưỡng". Vì vậy, bản thiết kế quy hoạch Đà Lạt của các kiến trúc sư Pháp như Ernest Hébrard năm 
1923, Louis Georges Pineau năm 1933, Mondet năm 1940, và Jacques Lagisquet năm 1943 đều ưu tiên dựa vào dạng địa hình vốn có, hài hòa, và tôn trọng môi trường sinh thái tự nhiên. Họ đã xây dựng các con đường nhỏ và ngắn ôm theo các thế đồi núi và ao hồ. Đường sá được quy hoạch không có các trục đường xuyên tâm, không có các trục đường thẳng tắp, và không có giao thông nhanh. Mật độ xây dựng nhà cửa được quy hoạch cực thấp, có sự khống chế về độ cao, và chủ yếu là nấp mình dưới các tán cây xanh. Trong bản vẽ quy hoạch Đà Lạt năm 1933, Louis Georges Pineau luôn đề cao nguyên tắc "bảo vệ vẻ đẹp tự nhiên, duy trì các danh lam thắng cảnh của Đà Lạt, mở rộng hồ nhân tạo với kiểu thành phố vây quanh hồ, phát triển những vườn hoa, thiết lập những khu vực phù hợp với địa phương và khí hậu” (Nguyễn, 2018, tr. 199). Sự hấp dẫn và quyến rũ của đô thị cao nguyên non trẻ này đã thu hút đông đảo người Pháp đến nghỉ dưỡng và cư trú. Ngay từ sớm, người Pháp đã thừa nhận ảnh hưởng tích cực của điều kiện tự nhiên Đà Lạt đến sức khỏe và tâm lý của những người Pháp sinh sống và nghỉ dưỡng ở đây-điều mà họ khó có được tại những khu vực khác ở Việt Nam. Đại úy Debay, người dẫn dắt một đoàn thám hiểm khảo sát Trung kỳ vào năm 1900 đã nhận định: "Người da trắng sẽ chết dần chết mòn bởi cái nóng bức và ẩm thấp vùng nhiệt đới. Tính cách của họ trở nên cáu kỉnh hơn, cảm xúc của họ quá khích hơn, khó chịu hơn, và cách duy nhất để chữa trị là trốn tránh nguyên nhân gây ra nó và tìm một nơi nghỉ dưỡng trên miền cao thuộc địa" (trích trong Eric, 2015, tr. 55). Bác sĩ Haueur viết: "một vài gia đình người Âu ở Đà Lạt gây ấn tượng cho chúng ta bởi sức khỏe của họ không kém gì những người nông dân Pháp. Da dẻ của họ hồng hào, thậm chí hơi đỏ. Họ là những người khỏe mạnh và béo tốt"; và Theo Tardif: "những cảm giác mới tuyệt vời: Không mũ, không nóng, không cần những viên đá lạnh, không cần mùng, Chúa đã phù hộ cho Đà Lạt. Nhờ có khu nghỉ dưỡng vùng cao này, tất cả những khó chịu và khốn khổ của Đông Dương đã lập tức tiêu tan" (trích trong Eric, 2015, tr. 95,151). Hay lúc gặp phải khó khăn khi về thăm nhà trong dịp nghỉ phép do thế chiến thứ nhất bùng nổ thì "người Âu muốn đến nghỉ dưỡng ở Đà Lạt, một vùng có khí hậu trong lành gợi nhớ đến hình ảnh của cố hương: Những đỉnh núi tròn của dãy Vosges, những đỉnh núi cao của Pyrénées, thác nước, và rừng thông của vùng Alpes và miền Trung nước Pháp (Nguyễn, 2018, tr. 130-162); "Đà Lạt như một người phục hồi sinh lực cho chủng tộc da trắng" (Eric, 2015, tr. 108). Vì vậy mà dưới thời thuộc địa, Đà Lạt được ví là "Dat Aliis Laetitiam Aliis Temperiem" (Mang niềm vui cho một số người và khí hậu ôn hòa cho những người khác) và cho rằng địa danh Đà Lạt là sự kết hợp khéo léo của cụm từ trên (Eric, 2015, tr. 152). Như vậy, khi hòa mình trong cảnh quan thiên nhiên Đà Lạt, người Pháp ở thuộc địa như tìm lại được nhịp sống vốn có của mình ở châu Âu.

Cùng với quá trình xây dựng và phát triển của thành phố, từ đầu thập niên 1930, người Việt từ nhiều vùng đất nước đã đến Đà Lạt để làm công nhân cầu đường, xây dựng nhà cửa và đồn điền của các chủ thầu Pháp. Về sau, số lượng người Việt ở Đà Lạt ngày càng tăng lên thông qua các luồng di cư đến lập nghiệp và tạo thành các xóm làng trù phú. Mặc dù có nguồn gốc vùng miền khác nhau, nhưng trải qua quá trình cộng cư, cộng đồng người Việt ở Đà Lạt đã sớm hình thành nên lối sống, văn hóa ứng xử, phong cách riêng, và có nhiều điểm khác biệt so với cư dân ở nhiều đô thị khác trong cả nước, với ba đặc trưng được giới nghiên cứu đưa ra là "hiền hòa, thanh lịch, mến khách". Đó cũng là những đặc điểm phong cách mà những ai đã từng đến Đà Lạt, tiếp xúc, gặp gỡ, và làm việc với người Đà Lạt đều dễ dàng cảm nhận được. Có nhiều yếu tố để hình thành nên phong cách sống của người Đà Lạt. Trong đó, tiền đề đầu tiên là do tác động của môi trường tự nhiên, địa 
hình, khí hậu, và cảnh quan đặc thù của vùng cao nguyên Lang Biang. Trước hết, không gian sống bình yên đã tạo cho người Đà Lạt có tính cách nhẹ nhàng, từ tốn, và ưa chuộng tĩnh lặng hơn là ồn ào, huyên náo. Khí hậu ôn hòa và mát mẻ làm cho người Đà Lạt sống hiền hòa, điềm đạm, ít ghen đua, kèn cựa, và ngại làm mất lòng người khác. Hòa mình trong cảnh quan thơ mộng, người Đà Lạt yêu thiên nhiên và rất thích trồng hoa trong vườn nhà để nâng niu và chăm sóc. Vì vậy, không khó để bắt gặp những khoảng không gian xanh đầy hoa lá nơi góc sân, trên ban công, hay nơi cửa sổ nhà ở của người Đà Lạt. Mỗi ngày, họ thường dành một ít thời gian để chăm sóc, thưởng thức, và xem như một thú vui tao nhã.

Khí hậu ở Đà Lạt lạnh và mát quanh năm đã tạo phong cách ăn mặc đặc trưng cho người dân nơi đây. Các mẹ, các chị, các em, từ người già cho đến người trẻ, nam giới hay phụ nữ ở Đà Lạt thường có sự ưu tiên cho những trang phục kín đáo và lịch sự. Thậm chí có lúc thời tiết không lạnh lắm, nhưng khi ra đường là nhất quyết phải ăn vận chỉnh tề, phải có áo dài tay. Dù là đi chợ ở gần nhà, họ cũng phải thay đổi quần áo và chải chuốt đầu tóc gọn gàng. Do đó, hình ảnh của người Đà Lạt trong mắt của những người từ nơi khác đến lúc nào cũng ăn mặc chỉnh tề và lịch sự. Đà Lạt có nguồn đất dồi dào, màu mỡ, và mật độ dân cư thưa thớt là điều kiện lý tưởng cho người dân sinh sống và phát huy thế mạnh trồng rau hoa thương phẩm để có cuộc sống khấm khá. Trong sản xuất nông nghiệp, mặc dù phải lao động tay, nhưng với những điều kiện khí hậu mát mẻ của Đà Lạt đã không làm cho họ phải tốn quá nhiều sức lực và hao mòn về thể chất như những người nông dân ở các vùng có khí hậu khô nóng và khắc nghiệt. Có lẽ cũng do điều này mà hình ảnh về người nông dân chân lấm tay bùn, một nắng hai sương như những vùng miền khác hiếm thấy tại Đà Lạt. Thậm chí nhiều người cả đời là nông dân nhưng khi nhìn qua phong thái và cách ứng xử, cứ ngỡ họ là những trí thức, công chức nhà nước, chứ không phải là những người lao động chân tay. Ngoài ra, vẻ đẹp của cảnh quan thiên nhiên cũng góp phần hình thành cho người Đà Lạt lối sống lãng mạn, thanh lịch, đơn giản mà quý phái. Không phải ngẫu nhiên, Đà Lạt được xem là "thiên đường" của thi thơ, nhạc, họa, và là nơi từng gắn bó của nhiều nhạc sĩ, ca sĩ, thi sĩ nổi tiếng. Họ đã chọn Đà Lạt và xem đây như một nơi để lấy cảm hứng sáng tác hoặc làm điểm xuất phát trong sự nghiệp làm nghệ thuật của mình (Nguyễn, 2017, tr. 16-19). Nhiều sắc thái thiên nhiên của Đà Lạt từ cảnh hoàng hôn, tiếng thông reo, hay thác nước chảy cho đến những con đường mờ sương vắng người qua lại... đều được xem là nguồn cảm hứng bất tận cho các nghệ sĩ đưa vào trong các tác phẩm nghệ thuật của mình. Chính vì vậy, trong từng ý thơ hay lời nhạc của họ luôn có sự hiện hữu về bóng dáng của những cảnh vật và con người Đà Lạt một cách sinh động và lãng mạn mà không một nơi nào có thể tìm thấy được. Qua đó, mỗi con người Đà Lạt cũng dường như tìm thấy được hình ảnh của chính mình về tính cách, lối sống, và tâm tư tình cảm qua những tác phẩm nghệ thuật này. Vì vậy, tất cả những tinh hoa và tinh túy được du nhập từ nền văn hóa phương Tây, nền giáo dục uyên bác, cũng như sự cống hiến về nghệ thuật của các văn, nghệ sĩ cho vùng đất này đã làm cho Đà Lạt hơn bao giờ hết đã trở thành một nơi mà người ta có thể dùng tất cả những mỹ tự đẹp nhất để dành cho nó. Sống trong một môi trường sinh thái tự nhiên và văn hóa như vậy, con người Đà Lạt đã biết thụ hưởng và "gọt dũa" mình nhiều hơn để có thể tạo ra sự hài hòa trong tổng thể con người với điều kiện tự nhiên nơi đây. Từ đó, tạo nên một hình ảnh con người Đà Lạt lãng mạn, với tính cách thanh lịch, hiền hòa, và thân thiện như chính cái khung cảnh thiên nhiên của nó.

Rõ ràng, cùng với những tác động từ môi trường xã hội, môi trường tự nhiên đã thôi thúc, tác động, và ảnh hưởng lớn đến việc hình thành nên tính cách của con người 
nơi đây. Những người con xa xứ từ mọi miền Tổ quốc đến với Đà Lạt đã không quản ngại khó khăn trong buổi đầu lập nghiệp nơi vùng đất mới. Họ đã mang theo mình sự chịu thương chịu khó của người dân nghèo vùng Nam- Ngãi-Bình-Phú; Sự tỉ mẫn và chặt chẽ của người Huế; hay Những nét thanh lịch của người Tràng An xưa. Họ đã sống ở Đà Lạt và được tiếp nhận nhiều tinh hoa từ văn hóa Âu châu, nền giáo dục mang tầm cỡ quốc tế, thiên đường của thi thơ, nhạc, họa... đã sớm nở rộ và để lại dấu ấn đậm nét tại nơi đây. Tất cả như hòa quyện cùng với điều kiện tự nhiên nơi đất mới để hình thành cho họ một phong cách mới-phong cách của "những người Đà Lạt ".

\section{NHậN ĐỊNH CHUNG}

Ngay từ khi mới hình thành, với ưu thế nổi trội của mình về điều kiện tự nhiên so với nhiều vùng miền khác, Đà Lạt luôn có nhiều cơ hội cho sự phát triển mang dáng dấp của một đô thị sang trọng, quý tộc, và thiên về xu hướng nghỉ dưỡng hơn là sự ồn ào, sôi động của một thành phố công nghiệp. Sinh sống trên vùng cao nguyên đất rộng, người thưa, không gian thoáng đãng, cảnh quan hữu tình, khí hậu mát mẻ, và ôn hòa quanh năm, cộng đồng người Việt ở Đà Lạt đã sớm hình thành nên phong cách sống chậm rãi, nhẹ nhàng, tình cảm, "hiền hòa, thanh lịch, mến khách". Ngày nay, sự thay đồi môi trường tự nhiên (sự suy giảm mật độ cây xanh trong thành phố, tăng nhiệt độ, và cảnh quan bị phá vỡ), cùng với những biến đổi của bối cảnh kinh tế, xã hội, và văn hóa (sự gia tăng thành phần dân nhập cư, sự du nhập lối sống của một đô thị sôi động, các vấn đề phát triển kinh doanh du lịch...) đã có sự tác động không nhỏ đến văn hóa của người Đà Lạt. Phong cách người Đà Lạt "hiền hòa, thanh lịch, mến khách" cũng ít nhiều có sự thay đổi đi cùng với sự đổi thay của những tiền đề đã tạo ra chúng. Chính vì vậy, khi bàn đến những giải pháp để giữ gìn và phát huy phong cách người Đà Lạt, cần thiết quan tâm đến việc bảo tồn, tôn tạo cảnh quan, và môi trường sinh thái của đô thị cao nguyên này.

\section{TÀI LIỆ THAM KHẢO}

Eric, T. J. (2015). Đỉnh cao đế quốc-Đà Lạt và sự hưng vong của Đông Duơng thuộc Pháp (V. P. Phạm, \& T. C. Bùi, Dịch). Hà Nội, Việt Nam: NXB. Hồng Đức.

Nguyễn, H. T. (2018). Đà Lạt năm xuza. Thành phố Hồ Chí Minh, Việt Nam: NXB. Trẻ.

Nguyễn, V. N. (2017). Đà Lạt một thời hương xa. Thành phố Hồ Chí Minh, Việt Nam: NXB. Trẻ.

Nguyễn, V. T. (2019). Từ tính cách đến phong cách người Đà Lạt: Tiếp cận lý thuyết nhân học văn hóa và khung phân tích. Tạp chí Khoa học Đại học Đà Lạt, 9(4), 73-86.

Phạm, Đ. D. (2002). Tù văn hóa đến văn hóa học. Hà Nội, Việt Nam: NXB. Văn hóa Thông tin.

Trương, T. L. H. (2018). Phong cách sống trong quan niệm của các học giả phương Tây. Trong Trường Đại học Đà Lạt (Ed), Kỷ yếu HTKH Giũ gìn và phát huy phong cách hiền hòa, thanh lịch, mến khách của người Đà Lạt (tr. 5-20). Lâm Đồng, Việt Nam: NXB. Trường Đại học Đà Lạt.

Vũ, M. C. (2004). Nhân học văn hóa-Con người với thiên nhiên, xã hội, và thế giới siêu nhiên. Hà Nội, Việt Nam: NXB. Chính trị Quốc gia. 